MBN TM -55583

\title{
THE DETERMINATION OF BARIUM IN G-1 AND W-1 BY ISOTOPE DILUTION
}

\author{
BY \\ C. C. SCHNETZLER \\ H. H. THOMAS \\ JOHN A. PHILPOTTS
}

GPO PRICE \$

CFSTI PRICE(S) \$

JULY 1966

$\mathrm{Ha}$ sopy $(\mathrm{HC}) \perp+O O$

Microfiche (MF)

50

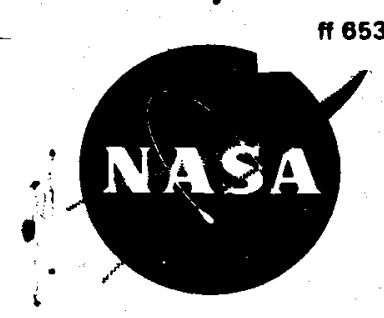

GODDARD SPACE FLIGHT CENTER GREENBELT, MD.
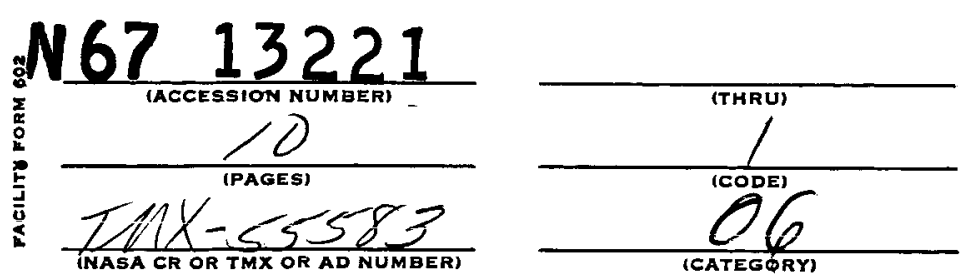
The Determination of Barium in $\mathrm{G}-1$ and $\mathrm{W}-1$ by Isotope Dilution

The wide range of reported values for barium in the rock standards G-1 and $W-1$ indicate that serious analytical difficulties have been experienced in the determinations of this element in rocks and minerals. The range of reported values in G-1 is from 900 to $3000 \mathrm{ppm}$ and in W-1 from 120 to 390 ppm (Stevens and others, 1960; Fleischer and Stevens, 1962; Fleischer, 1965). These barium abundances were determined by many different analytical techniques, including standard chemical analysis, emission spectrography, X-ray fluorescence, and spark source mass spectrometry. Fleischer (1965), in his latest review of the data on $G-1$ and $W-1$, noted the poor quality of the barium results and advocated the development of new analytical techniques for the analysis of barium .

The purpose of this note is to report on barium determinations obtained by mass spectrometric stable isotope dilution. This technique, to our knowledge, has not been applied previously in analysis for this element, although it has been successfully applied to a number of other elements during the past ten to fifteen years, particularly in geochronology. A description of the general technique is given by Webster (1960).

Briefly, our method of analysis contained the following steps. A spike, enriched approximately $90 \%$ in the mass 136 isotope, was added to approximately 0.5 grams of weighed, powdered sample. The sensitivity of barium in the thermal ionization mass spectrometer is so high that much less sample could have been used - less than one microgram of barium is needed for an analysis. However, the large samples were used to reduce contamination errors, to obviate any small scale sampling errors, and because the analyses were made in conjunction with rare-earth element analyses (Schnetzler et al, 1966) 
for which larger samples were necessary in the determination of some of the less abundant rare earths. The samples were dissolved in $\mathrm{HF}$ and $\mathrm{HClO}_{4}$, and the solutions eluted with $\mathrm{HCl}$ through vycor chromatographic columns filled with Dowex 50W, $8 \%$ cross linked, 200-400 mesh ion exchange resin. The fractions containing barium were collected, evaporated to dryness, and picked up in a small amount of $2 \mathrm{~N} \mathrm{HCl}$ by a vycor syringe. Each sample was then dried on the two rhenium side filaments of a conventional triple filament source, and analyzed in a $12^{\prime \prime}, 60^{\circ}$ sector, surface ionization mass spectrometer. The 134 to 138 mass range was scanned magnetically and the concentration of barium in the sample was calculated from the resulting mass spectrum.

The concentration of the spike was calibrated with "spec-pure" $\mathrm{BaCO}_{3}$ obtained from the Johnson, Matthey Co. The result was within $0.2 \%$ of the concentration calculated from the weight of spike, that was obtained as $\mathrm{Ba}\left(\mathrm{NO}_{3}\right)_{2}$, from the Oak Ridge National Laboratory. Likewise, the per cent of the mass 136 isotope in the spike, as determined by an independent isotope ratio analysis, was within $0.3 \%$ of the per cent enrichment reported by Oak Ridge. A blank analysis, as determined by mass spectrometric analysis of pure spike which had been put through the complete chemical procedure, suggested that contamination was quite small - approximately 0.3 micrograms.

Results of three separate, independent analyses of G-1 and two of W-1 are given in Table 1. The precisions shown are only internal, in that they are the standard deviation of the mean of the number of determinations $(n)$, each determination being calculated from two scans. It should be noted that for G-1 the independent analyses differ by more than the internal precision of the analyses; this may be ascribed to sample inhomogeneity, fractionation of the isotopes during the mass spectrometric analysis, or variable 
contamination during the chemical preparation of the samples. The latter suggestion is unlikely in view of the blank determination. The actual precision of the isotope dilution method of analysis for barium in the range found in G-1 and $W-1$ appears to be 1 to $2 \%$. Thus, we suggest the barium concentration is $1040 \pm 20 \mathrm{ppm}$ in $\mathrm{G}-1$ and $158 \pm 2 \mathrm{ppm}$ in $\mathrm{W}-1$. However, rare-earth analyses (Haskin and Gehl, 1963; Towell et al., 1965; Schnetzler et al., 1966) suggest that sample inhomogeneity of G-1 may be quite important, and the value of 1040 ppm Ba for G-1 might represent only the concentration in the sample analyzed.

C. C. Schnetzler

H. H. Thomas

John A. Philpotts 
Table 1

Concentration of Barium in $G-1$ and $W-1$, in ppm by weight

\begin{tabular}{|c|c|c|}
\hline & G-1 & W-1 \\
\hline & $1038 \pm 4(\mathrm{n}=32)$ & $157.5 \pm 1.0(\mathrm{n}=13)$ \\
$1028 \pm 3(\mathrm{n}=28)$ & $158.6 \pm 0.4(\mathrm{n}=24)$ \\
& $1051 \pm 5(\mathrm{n}=16)$ & \\
\hline Avg.: & 1039 & 158.0 \\
\hline & & \\
\hline (Flest value" & 1220 & 180 \\
\hline
\end{tabular}




\section{References}

Fleischer, Michael (1965), Summary of new data on rock samples G-1 and W-1, 1962-1965. Geochim. et Cosmochim. Acta, 29, 1263-1283.

Fleischer, Michael and Stevens, R. E. (1962), Summary of new data on rock samples G-1 and W-1, Geochim. et Cosmochim. Acta, 26, 525-543.

Haskin, Larry and Gehl, M. A. (1963), The rare-earth contents of standard rocks G-1 and $W-1$ and their comparison with other rare-earth distribution patterns, J. Geophys. Res., 68, 2037-2043.

Schnetzler, C. C., Thomas, H. H. and Philpotts, J. A., (1966), Rare earth analysis by a mass spectrometric isotope dilution technique, in preparation.

Stevens, R. E. and others, (1960), Second report of a cooperative investigation of the composition of two silicate rocks, $\underline{U} \cdot \underline{S}$. Geol Surv. Bull, $\underline{113}$, $1-126$.

Towe11, D. G., Volfovsky, Regina and Winchester, J. W., (1965), Rare-earth abundances in the standard granite $G-1$ and standard diabase W-1, Geochim. et Cosmochim. Acta, 29, 569-572.

Webster, R. K., (1960), Mass spectrometric isotope dilution analysis, Chapter VII in Methods in Geochemistry, ed. by A. A. Smales and L. R. Wager, Interscience, 202-246. 